Groot, K. de, Triemstra, M., Paans, W., Francke, A.L. Quality criteria, instruments and requirements for nursing documentation: a systematic review of systematic reviews. Journal of Advanced Nursing (JAN): 2019, 7, p. 1379-1393

$\begin{array}{lll}\text { Postprint version } & : & 2.0 \\ \text { Journal website } & : & \text { https://onlinelibrary.wiley.com/doi/pdf/10.1111/jan.13919 } \\ \text { Pubmed link } & : & \\ \text { DOI } & : 10.1111 / \text { jan.13919 }\end{array}$

This is a Nivel certified Post Print, more info at nivel.nl

\title{
Quality criteria, instruments, and requirements for nursing documentation: A systematic review of systematic reviews
}

\author{
Kim De Groot ${ }^{1,2}$, Mattanja Triemstra ${ }^{1}$, Wolter Paans ${ }^{3}$, Anneke L. Francke ${ }^{1,4}$ \\ ${ }^{1}$ Netherlands Institute for Health Services Research (Nivel), Utrecht, The Netherlands \\ ${ }^{2}$ Thebe Wijkverpleging [Home care organisation], Tilburg, The Netherlands \\ ${ }^{3}$ Research Group Nursing Diagnostics, Hanze University of Applied Sciences, Groningen, The \\ Netherlands \\ ${ }^{4}$ Department of Public and Occupational Health, Amsterdam Public Health research institute/VU \\ Medical Centre, Amsterdam, The Netherlands
}

\begin{abstract}
Aim: To obtain an overview of existing evidence on quality criteria, instruments, and requirements for nursing documentation.

Design: Systematic review of systematic reviews.

Data sources: We systematically searched the databases PubMed and CINAHL for the period 2007-April 2017. We also performed additional searches.

Review methods: Two reviewers independently selected the reviews using a stepwise procedure, assessed the methodological quality of the selected reviews, and extracted the data using a predefined extraction format. We performed descriptive synthesis. Results: Eleven systematic reviews were included. Several quality criteria were described referring to the importance of following the nursing process and using standardized nursing terminologies. In addition, some evidence-based instruments were described for assessing the quality of nursing documentation, such as the D-Catch. Furthermore, several requirements for formats and systems of electronic nursing documentation were found that refer to the importance of user-friendliness and development in consultation with nursing staff.

Conclusion: Aligning documentation with the nursing process, using standard terminologies, and using user-friendly formats and systems appear to be important for high-quality nursing documentation. The lack of evidence-based quality indicators presents a challenge in the pursuit of high-quality nursing documentation. Impact: There is uncertainty in nursing practice about which criteria have to be met to achieve high-quality documentation.
\end{abstract}


- Aligning documentation with the nursing process, using standard terminologies, and using user-friendly formats and systems appear to be important.

- These findings can help nursing staff and care organizations enhance the quality of nursing documentation.

\section{INTRODUCTION}

High-quality nursing documentation is essential for the quality and continuity of nursing care (Jefferies, Johnson, \& Griffiths, 2010; Matic, Davidson, \& Salamonson, 2010; Paans, Nieweg, van der Schans, \& Sermeus, 2011; Urquhart, Currell, Grant, \& Hardiker, 2009; Wang, Hailey, \& Yu, 2011). Nursing documentation can enhance effective communication between healthcare professionals, which makes it vital for the patient's safety (Wang et al., 2011). Therefore, the quality of nursing documentation is stressed internationally as being of the utmost importance (Blair \& Smith, 2012; Jefferies et al., 2010). However, several studies show that the quality of documentation is moderate to poor (Müller-Staub, Lavin, Needham, \& van Achterberg, 2006; Wang et al., 2011). We have conducted a systematic review to obtain an overview of the existing evidence about nursing documentation, and thereby help nursing staff achieve high-quality nursing documentation.

\subsection{Background}

Inadequacies in nursing documentation are frequently found in the documentation of patients' care needs, interventions, and progress reports (Paans, Sermeus, Nieweg, \& Van der Schans, 2010; Tuinman, De Greef, Krijnen, Paans, \& Roodbol, 2017). These inadequacies are related to the fact that the nursing process is not always used as the point of departure in the documentation (Blair \& Smith, 2012). The nursing process is a relational, systematic, problem-solving method that facilitates nurses in problem-solving, critical thinking, and clinical decision-making (Paans et al., 2011). The main elements of the nursing process are: (a) assessment, (b) nursing diagnoses, (c) planning, (d) implementation, and (e) evaluation and —if applicable — handovers (Björvell, Thorell-Ekstrand, \& Wredling, 2000).

As the use of electronic health records steadily increases, the quality of nursing documentation requires more attention than ever (Jefferies et al., 2010). A recent survey in the Netherlands showed that $90 \%$ of the hospital nursing staff and $62 \%$ of the nursing staff in long-term older people care already mainly or exclusively used electronic health records for documentation (Wouters et al., 2017). Other Dutch and international studies show that nurses often experience problems in the digital exchange of information about nursing care (De Groot, Paans, De Veer, \& Francke, 2017; Lavin, Harper, \& Barr, 2015; Sockolow, Liao, Chittams, \& Bowels, 2012). These problems are related to the structure of the digital formats and the poor match between the different digital systems that nurses use (De Groot, Paans, et al., 2017). Another challenge is that nurses in different healthcare settings use a different professional vocabulary (i.e., words and terms) to describe elements of the nursing process and nursing care (Lavin et al., 2015; Sockolow et al., 2012).

Unambiguous language is an important prerequisite for exchanging electronic information without the risk of misinterpretation. By "unambiguous language" we mean in this regard that documented information is open to only one explanation (Kieft et al., 2017; Randorff Højen \& Rosenbeck Gøeg, 2012; Westra et al., 2015). Consequently, words and terms that healthcare professionals use can be linked with each other in the digital systems (Kieft et al., 2018). Unambiguous language can facilitate the exchange of electronic information throughout healthcare settings (Kieft et al., 2017). Besides, using unambiguous language also creates opportunities for the reuse of information in, for instance, nursing research or quality benchmarks.

However, the use of unambiguous language is not self-evident. In nursing practice, a wide variety of terminologies are being used. Various terminologies are being used across and in different care settings, as shown in a recent survey in the Netherlands (De Groot, De Veer, Paans, \& Francke, 2017). These terminologies are often developed locally; others are standard terminologies. The American Nursing Association has recognized 12 standard nursing terminologies (e.g., the Omaha System, North 
American Nursing Diagnosis Association (NANDA), Nursing Interventions Classification, and Nursing Outcomes Classification) (The Office of the National Coordinator for Health Information Technology, 2017). These terminologies - often known as classification systems - are intended as a guide for documentation and to make sure that the nursing process is documented systematically and unambiguously (Müller-Staub, Needham, Odenbreit, Lavin, \& van Achterberg, 2007; Tastan et al., 2014). However, the words and terms used in the standard terminologies are themselves different, which is particularly challenging in situations where nurses handover information to professionals in other settings using different standard terminologies (Kieft et al., 2017).

So far, there is uncertainty in nursing practice about which criteria must be met to achieve high-quality documentation, particularly about the challenges described.

\section{THE REVIEW}

\subsection{Aim}

The aim of this systematic review was to give insight into existing evidence from systematic reviews of nursing documentation. The review questions guiding this systematic review were:

\section{What quality criteria should nursing documentation meet?}

More specifically:

1a. What quality criteria or indicators apply for aligning the documentation with the nursing process?

1 b. What quality criteria or indicators apply for "unambiguous language"?

2.What instruments are available to give insight into the quality of nursing documentation?

3.What requirements apply for digital formats and electronic nursing documentation systems?

\subsection{Design}

A systematic review of systematic reviews was conducted that followed the methodological recommendations of Smith, Devane, Begley, and Clarke (2011). We chose to review existing systematic reviews, rather than individual studies, since we knew beforehand that there had already been some relevant reviews. We wanted to compare the findings of these reviews so that we could give nursing practice the best evidence available. In line with the recommendations of Smith et al. (2011), reporting in this systematic review follows the guidelines in the PRISMA statement (Moher, Liberati, Tetzlaff, Altman \& PRISMA Group, 2009).

\subsection{Search methods}

In April 2017, searches were performed in the electronic databases PubMed and CINAHL for relevant reviews published in 2007 or later. For 2007 as the start year was chosen as there has been a big rise in the use of electronic health records in the past decade. Because our specific interest is in electronic health records, a longer period therefore seemed inappropriate.

The search strategy was drafted in collaboration with a librarian and included the following terms linked with AND and OR: 'nursing', 'handoffs', 'records', 'documentation', 'quality', 'indicators', and 'accuracy'. For the full search strategies see Supporting Information Data S1.

In addition, searches were performed in the international guideline websites Guidelines International Network, National Institute for Health and Care Excellence, and National Guideline Clearinghouse (www.g-i-n.net; date accessed 24 April 2017, www.nice.org.uk; date accessed 24 April 2017, www.guideline.gov; date accessed 24 April 2017) to identify guidelines involving relevant systematic reviews. Furthermore, free text searches were conducted using Google, the references in the included 
publications were studied, and experts in the field of nursing documentation were consulted to identify relevant reviews.

The review selection was performed using a stepwise procedure with the aid of the screening tool Covidence (www.covidence.org). First, two authors ( $\mathrm{AF}$ and $\mathrm{KdG}$ ) independently reviewed the titles and abstracts of the references identified in PubMed and CINAHL. Any discrepancies concerning the inclusion or exclusion were resolved by discussion.

Secondly, the full texts of the references that remained were independently assessed for eligibility by two authors (MT and KdG). A third author (AF) was consulted in case of disagreement between the two authors.

The following eligibility criteria were used in the selection process. The publication had to:

1.describe quality criteria, quality indicators, or quality measurement instruments for nursing documentation;

2.describe requirements for formats or systems of electronic nursing documentation;

3.concern nursing staff (whether or not combined with other professionals);

4.be published in English or Dutch;

5.be a systematic review, meaning any type of review that includes systematic review processes (i.e., the review describes questions or aims, inclusion criteria, and search strategies and searches are conducted in PubMed and at least one other database); and

6.be published in 2007 or later.

\subsection{Search outcome}

The searches led to 3,088 references, after removing duplicates. Based on the title and abstract screening, 3,044 references were excluded. Based on the full text assessments, a further 33 publications were excluded (see Supporting Information Data S2). Thus, the selection process resulted in 11 systematic reviews for inclusion in this systematic review. The flow chart in Figure 1 outlines the selection process.

\section{[Figure 1]}

\subsection{Quality appraisal}

Two authors (MT and KdG) independently assessed the methodological quality of all the included reviews using the adapted version of the Assessing the Methodological Quality of Systematic Reviews (AMSTAR) tool (Shea, Bouter, et al., 2007; Shea, Grimshaw, et al., 2007). The adaptations were in line with the recommendations of Burda, Holmer, and Norris (2016) and concerned improvements for the usability, reliability, and validity of the tool.

Even though the selected reviews mentioned different review designs, they all included systematic review processes. Following the recommendations of Smith et al. (2011) the AMSTAR tool was therefore judged as an appropriate tool to use.

Each review received an individual score between 0 and 10 . These scores were classified as follows: reviews with scores $0-4$ were considered as low methodological quality, scores 5-8 were considered as average quality, and scores 9-11 were considered as high quality. Small discrepancies in the scores of the two authors were easily resolved by means of discussion until consensus was reached.

The assessment of the methodological quality showed that only one review was of a high quality. Six reviews were of average quality and four of low quality (Table 1). Most reviews scored poorly on the items of "assessing the risk of bias in each study that was included," "assessing the likelihood of 
publication bias," "assessing the quality of the body of evidence," and "including relevant grey literature." Five reviews did not report their source of funding and one review received no funding (Table 1). The funding sources for the other five reviews were not likely to be a source of bias in the review's conclusions. Irrespective of the AMSTAR score, all the selected reviews were used for the extraction of data since they all contained relevant data for answering the research questions.

\section{[table1]}

\subsection{Data abstraction}

The selected reviews were divided among two authors (MT and KdG), who independently extracted the data based on a predefined extraction format. The key findings that were extracted were the type of documentation, general quality criteria, quality criteria concerning the nursing process, quality criteria concerning unambiguous language, instruments used to measure the quality of nursing documentation, requirements for electronic nursing documentation, and prerequisites for electronic nursing documentation.

Another author (WP) cross-checked the content of the extraction table for accuracy and completeness. Based on this check, only small adjustments had to be made in the extraction table. The extraction table provided the contents for Tables 2-4.

\section{[table 2] [table 3][table 4]}

\subsection{Synthesis}

Since the reviews concerned studies with heterogeneous study methods, a meta-analysis was not possible. We therefore performed a descriptive synthesis of the results. The findings in the Results section and the Conclusion section are discussed in relation to the methodological quality of the reviews. The conclusions in this systematic review were based on the conclusions and results that were presented in the included reviews. This method of synthesis is the same as that used in other systematic reviews of systematic reviews (Francke, Smit, De Veer, \& Mistiaen, 2008; Mistiaen, Francke, \& Poot, 2007).

\section{RESULTS}

\subsection{Study characteristics}

All of the included reviews present relevant information for answering the review questions. The 11 reviews cover a total of more than 450 research publications (with some overlap), mainly from Western Europe and America. Most of the underlying studies concern descriptive qualitative, quantitative, or mixed-method studies.

The reviews aim to give an overview of existing evidence on aspects of nursing documentation in general, or on electronic documentation in particular. The reviews focus on identifying the determinants of effective and safe documentation, giving a better understanding of terminologies or categorizations for documentation and identifying quality requirements and/or the effects of methods for documentation. Three reviews compare different terminologies and categorizations for nursing documentation (Blair \& Smith, 2012; Flemming \& Hübner, 2013; Urquhart et al., 2009).

Ten reviews focus specifically on nursing documentation. One review concerns general documentation, including documentation by nurses and other professionals (Flemming \& Hübner, 2013). Three reviews focus on documentation in hospitals (Kelley, Brandon, \& Docherty, 2011; Paans et al., 2011; Staggers \& Blaz, 2013) and one concentrates on long-term care (Meissner \& Schnepp, 2014). The remaining seven reviews either cover all care settings or do not specify the care setting. 
Eight of the included reviews focus on different forms of nursing documentation, including paper and electronic documentation. Three of these reviews also included studies of verbal handovers (Matic et al., 2010; Riesenberg, Leitzsch, \& Cunningham, 2010; Staggers \& Blaz, 2013). Two reviews looked exclusively at electronic documentation (Flemming \& Hübner, 2013; Meissner \& Schnepp, 2014) and one review did not specify the documentation method (Jefferies et al., 2010).

\subsection{Quality criteria for nursing documentation in relation to the nursing process and unambiguous language}

No detailed quality indicators for nursing documentation with performance norms, numerators, denominators, and measurement instructions were found. Nevertheless, the reviews did mention some more generally formulated quality criteria or requirements (see Table 2 ).

Four reviews state that a quality criterion for nursing documentation is that it must be aligned with the stages of the nursing process (Blair \& Smith, 2012; Flemming \& Hübner, 2013; Paans et al., 2011; Wang et al., 2011). For example, the review by Blair and Smith (2012) describes the methodological approach to documentation of considering the observations, interventions, and outcomes of care. They also state that alignment with the nursing process can be achieved through the use of categorizations, that is, a Swedish model describing well-being, integrity, prevention, and safety (the VIPS model), a format describing subjective data, objective data, assessment, plan, intervention, evaluation and revision (SOAP/SOAPIE), a format describing the history, observation, assessment and plan (HOAP), and a focus charting format (see Box 1 in Supporting Information Data S3).

The review by Flemming and Hübner (2013) mentions the use of the nursing process in the sense of a care plan that must be present at a handover. This care plan must document the interventions that are being performed, with supporting arguments for the choices that have been made.

Paans et al. (2011) also emphasize the documentation of supporting arguments for the choices that have been made, but then specifically in the case of nursing diagnoses as an important step in the nursing process. Nursing diagnoses should be formulated on the basis of assessments and conversations with the patient, and observations of the patient. In this context, the review by Paans et al. (2011) recommends applying clinical reasoning and using the problem-aetiology-symptoms (PES) structure.

The review by Wang et al. (2011) argues that the content of nursing documentation should correspond to five steps, namely assessment, diagnosis, goal, intervention, and evaluation.

In addition to alignment with the nursing process, seven of the 11 reviews mention the use of standard terminologies as a way of improving the accuracy of documentation (Blair \& Smith, 2012; Flemming \& Hübner, 2013; Paans et al., 2011; Riesenberg et al., 2010; Staggers \& Blaz, 2013; Urquhart et al., 2009; Wang et al., 2011). Box 1 gives an overview of terminologies and categorizations that are mentioned frequently in the reviews (see Supporting Information Data S3).

The review by Blair and Smith (2012) states that the use of electronic documentation involves a professional challenge in standardizing the words and terms used to create a language that can be used by all nurses in all healthcare settings. Wang et al. (2011) also stress the importance of a standardized nursing language, given that this uniform, controlled list of terms makes it possible to gather data on patients and the delivery of nursing care.

However, Riesenberg et al. (2010) mention in their review that in the specific case of handovers, there is unlikely to be a single standardized format available that will be appropriate for all settings where nurses work. Urquhart et al. (2009) also state that the formats for effective nursing documentation are likely to be just as diverse as nursing practice itself. 
We also considered the extent to which the existing quality criteria or requirements are evidencebased. As is clear from the above, the 11 reviews make statements about criteria that are important for good documentation. However, the strength of the evidence for these statements depends on two aspects. Firstly, it depends on the methodological quality of the reviews themselves; with the exception of the review by Urquhart et al. (2009), the quality of all the reviews was average or poor (see Table 1). Secondly, it depends on the strength of the evidence in the underlying studies. For example, three reviews conclude that there is some evidence (based on underlying studies) that the nursing process should be followed in the documentation (Blair \& Smith, 2012; Paans et al., 2011; Wang et al., 2011). Furthermore, three reviews conclude that there is some evidence (based on the underlying studies) for the use of standard terminologies in nursing documentation (Flemming \& Hübner, 2013; Paans et al., 2011; Wang et al., 2011).

\subsection{Instruments for measuring quality nursing documentation}

This review also focused on measurement instruments that can give insight into the quality of nursing documentation. Five reviews describe evidence-based instruments for measuring the quality of nursing documentation; see Table 3 (Flemming \& Hübner, 2013; Matic et al., 2010; Paans et al., 2011; Riesenberg et al., 2010; Wang et al., 2011).

The review by Paans et al. (2011) describes the Quality of Nursing Diagnosis instrument and the Dutch $D$-Catch instrument. The D-Catch instrument was originally developed to measure the accuracy of nursing documentation in hospitals (Paans et al., 2011). This instrument is based on the Cat-ch-Ing instrument, which is also described in the review by Wang et al. (2011). Specific items in the D-Catch and Cat-ch-Ing instruments focus on the quality of documentation of the nursing process. Other instruments mentioned by Wang et al. (2011) include Ehnfors and Smedby's comprehensiveness-inrecording instrument and the Quality of Nursing Diagnoses Interventions and Outcomes (Q-DIO) instrument. Specific items in the Q-DIO instrument concern the documented nursing diagnosis, interventions, outcomes, and their internal relationships. In addition, the reviews mentioned several checklists and minimum datasets that are derived from the Situation, Background, Assessment and Recommendation (SBAR) categorization (Flemming \& Hübner, 2013; Matic et al., 2010; Riesenberg et al., 2010).

\subsection{Requirements for electronic nursing documentation}

The review also considered requirements for formats and systems of electronic nursing documentation (see Table 4).

While the Cochrane review by Urquhart et al. (2009) did not yet show any evidence of measurable differences between electronic and paper documentation in the effects on nursing care or patient outcomes, the more recent review by Flemming and Hübner (2013) did give some evidence of the superiority of electronic documentation compared with documentation on paper.

Two reviews shed light on the specific quality requirements for electronic documentation, particularly with regard to user-friendliness and the investment in terms of time or workload. Matic et al. (2010) conclude that the effectiveness of electronic formats for documentation depends on the quality and design of the software. The review by Meissner and Schnepp (2014) lists a large number of quality requirements for electronic documentation, such as easy to access, easy to read, and easy to check and monitor information. All quality requirements mentioned by Meissner and Schnepp (2014) are presented in Box 2 in Supporting Information Data S3.

Five reviews also give specific preconditions or risks for electronic documentation.

The review by Meissner and Schnepp (2014) describes the following conditions: support for staff in determining what and which problems they should record, training for staff, and appropriate hardware, software, and technical functionality. 
The reviews by Flemming and Hübner (2013), Riesenberg et al. (2010) and Staggers and Blaz (2013) emphasize the importance of using standard formats for documentation. At the same time, Flemming and Hübner (2013) warn that the standard formats must not prevent a comprehensive account from being recorded. Prestructured formats sometimes appear unable to accommodate the important subjective and prospective information that is needed to tell the "whole story". Riesenberg et al. (2010) and Staggers and Blaz (2013) state that the standard formats must be customized to fit each area of nursing.

The review by Kelley et al. (2011) also mentions the advantages of prestructured formats, such as selection options and drop-down menus. At the same time, this review also points to the risks of structured formats, namely that nurses will not consider the actual nursing process so much, that the copy-paste function will encourage the copying of data that is no longer valid or accurate and that nurses will not give a complete description of the patients' situations. For the design and optimization of electronic formats, Kelley et al. (2011) propose basing these formats on the patient information that is necessary to ensure the delivery of safe care.

\section{DISCUSSION}

This systematic review of systematic reviews is the first to give an overview of the best available evidence about nursing documentation for nursing practice.

Firstly, this systematic review focussed on quality criteria for nursing documentation. The results show that quality indicators with performance norms are lacking. Despite the lack of these indicators, the reviews included do mention quality criteria for nursing documentation. Most reviews point out that nursing documentation needs to be aligned with the nursing process to obtain higher quality documentation (Blair \& Smith, 2012; Flemming \& Hübner, 2013; Paans et al., 2011; Wang et al., 2011).

The reviews also describe a wide range of terminologies and categorizations and refer to the importance of using standard terminologies (e.g., the Omaha System or NANDA) and standard categorizations (e.g., SBAR) (Blair \& Smith, 2012; Flemming \& Hübner, 2013; Paans et al., 2011; Riesenberg et al., 2010; Staggers \& Blaz, 2013; Urquhart et al., 2009; Wang et al., 2011). This wide range is remarkable, although in line with recent survey research identifying a great variety of terminologies and categorizations being used by nurses in different healthcare settings (De Groot, De Veer, et al., 2017). Often the same terminology or categorization is used in a given setting, but there is much variation between settings (De Groot, De Veer, et al., 2017). For example, the terminology Omaha System is often used in home care in the Netherlands, but not in hospital settings (De Groot, De Veer, et al., 2017). Besides, locally developed terminologies or categorizations are frequently used (De Groot et al., 2017).

Though the diversity in terminologies and categorizations is understandable given the diversity of nursing practice itself, it can cause problems in handover situations in particular. Previous research has shown that an unambiguous language is needed for exchanging information between settings without a risk of misinterpretation (Kieft et al., 2017; Lavin et al., 2015; Randorff Højen \& Rosenbeck Gøeg, 2012; Sockolow et al., 2012; Westra et al., 2015). For a genuine unambiguous language that applies across settings, the information from the current standard terminologies and categorizations used for nursing documentation has to be linked (Kieft et al., 2018). In the Netherlands, various national parties (including the Dutch Nurses Association) recently recommended incorporating the standard medical terminology SNOMED CT into the digital systems for nursing documentation. Using SNOMED CT does not mean that other terminologies have to disappear. The standard terminologies currently used by nurses, for example the Omaha System or NANDA, can continue to be used. SNOMED CT forms, as it were, an unambiguous language bridge between the existing systems (Kieft et al., 2017, 2018).

This development towards an unambiguous language could be essential for the quality of nursing documentation and for the patient's safety, particularly in handover situations. Besides, an unambiguous language can also help obtain data that can be used for multiple objectives: not only for 
documentation in nursing practice, but also for nursing research and quality benchmarks (Verheij, Curcin, Delaney, \& McGilchrist, 2018; Wang et al., 2011).

Secondly, this systematic review focussed on evidence-based instruments for measuring the quality of nursing documentation. Several instruments (e.g., the D-Catch instrument and the Q-DIO instrument) were found which tie in with the quality criterion of aligning nursing documentation with the nursing process (Paans et al., 2011; Wang et al., 2011). These evidence-based instruments could provide a framework for the further development of quality indicators with performance norms that could give a clear indication of the quality of nursing documentation. In this development trajectory, it is important to formulate norms for good-quality documentation that relate to the accuracy and efficiency of documentation, as suggested by the quality criteria that were found in this systematic review (Blair \& Smith, 2012; Flemming \& Hübner, 2013; Jefferies et al., 2010; Kelley et al., 2011; Matic et al., 2010; Meissner \& Schnepp, 2014; Paans et al., 2011; Riesenberg et al., 2010; Staggers \& Blaz, 2013; Urquhart et al., 2009; Wang et al., 2011). Recently, some initial steps have been taken in international nursing research towards such quality indicators, including norms for good-quality documentation (MüllerStaub, De Graaf-Waar, \& Paans, 2016).

Finally, this systematic review also focused on the requirements for electronic nursing documentation formats and systems. The reviews showed that electronic nursing documentation is preferred over documentation on paper, but it must be user-friendly and not require much investment in time (Flemming \& Hübner, 2013; Matic et al., 2010; Meissner \& Schnepp, 2014). To meet the precondition of user-friendliness, it is recommended that the digital formats and systems are developed in cooperation and discussion with nursing staff (Urquhart et al., 2009). There may be a task here for individual nurses, care organizations, and nurses' professional associations. In addition, the involvement of nurses in determining what should be recorded and training for nurses are important requirements (Meissner \& Schnepp, 2014; Urquhart et al., 2009).

Besides, this systematic review also indicates that standard formats play an important role in electronic documentation, given that these formats do not prevent nurses from documenting important information that is needed to tell the "whole story" about the patient. Room should always exist in the records for narrative texts detailing the unique situation of the individual patient (Flemming \& Hübner, 2013; Kelley et al., 2011).

Furthermore, similar to the variation in nursing terminologies or categorizations, the standard formats used in nursing practice also vary. Riesenberg et al. (2010) and Urquhart et al. (2009) note that there is no single structured format appropriate for the entirety of the diverse nursing practice. The reviews of Riesenberg et al. (2010) and Staggers and Blaz (2013) recommend that formats for nursing documentation should be tailored for specific nursing settings. This recommendation would increase the diversity in formats and could therefore negatively affect the comparability and linkage of nursing documentation. On the other hand, tailoring could enhance effective communication between nurses in a setting and therefore ensure the quality and safety of nursing care (Wang et al., 2011). Following the quality criteria that were found in this systematic review of systematic reviews, it is important that standardized nursing terminologies related to the nursing process remain the point of departure when customizing the digital formats and systems (Müller-Staub et al., 2016).

\subsection{Limitations}

Considerable research has been done to date on nursing documentation, as it became clear from the 11 systematic reviews involving a large number of underlying studies. The strength of this systematic review of systematic reviews is that it presents an overview of the state of the art of research done in this field. However, none of the systematic reviews included covered the last 5 years of research on this topic. This may be an issue, especially in a field in which technology and innovation have evolved quickly in the last years. 
Another limitation of this review is that with one exception, the quality of the reviews included was average or low. This means that firm conclusions cannot be drawn. However, the results from this review do point in certain directions. Though quality indicators could not be extracted, the reviews showed various quality criteria, instruments, and requirements for nursing documentation.

\section{CONCLUSIONS}

In this systematic review of systematic reviews, several quality criteria for nursing documentation were found referring to alignment with the stages in the nursing process and the use of standard terminologies. However, unambiguous language is not yet self-evident in nursing practice, where multiple standard terminologies are being used. SNOMED CT could offer a solution by linking the different terminologies and leading to an unambiguous language.

Furthermore, requirements were identified for formats and systems for electronic nursing documentation. It is important that these formats are user-friendly and are developed in consultation with nursing staff. For providing insight into the quality of nursing documentation, various evidencebased instruments are available that tie in with the quality criteria found. Despite these conclusions, quality indicators with clear performance norms for nursing documentation are still lacking, which is a challenge for future research.

\section{ACKNOWLEDGEMENTS}

We would like to thank Letty Hartman for her help in drafting the search strategies, and Clare Wilkinson for her help with language editing.

\section{CONFLICT OF INTEREST}

No conflict of interest has been declared by the authors.

\section{AUTHOR CONTRIBUTIONS}

All authors have agreed on the final version and meet at least one of the following criteria [recommended by the ICMJE (http://www.icmje.org/recommendations/)]:

- substantial contributions to conception and design, acquisition of data, or analysis and interpretation of data;

- drafting the article or revising it critically for important intellectual content

\section{References}

1. Björvell, C., Thorell-Ekstrand, I., \& Wredling, R. (2000). Development of an audit instrument for nursing care plans in the patient record. Quality in Health Care, 9, 6-13. https://doi.org/10.1136/qhc.9.1.6

2. Blair, W., \& Smith, B. (2012). Nursing documentation: Frameworks and barriers. Contemporary Nurse, 41(2), 160-168. https://doi.org/10.5172/conu.2012.41.2.160

3. Burda, B. U., Holmer, H. K., \& Norris, S. L.. (2016). Limitations of a measurement tool to assess systematic reviews (AMSTAR) and suggestions for improvement. Systematic Reviews, 5, 58. https://doi.org/10.1186/s13643-016-0237-1

4. De Groot, K., De Veer, A. J. E., Paans, W., \& Francke, A. L. (2017). Verpleegkundige verslaglegging: Hbo'ers meest positief [Nursing documentation: Nurses with bachelor's degree are the most positive]. TVZ: Tijdschrift Voor Verpleegkundigen, 127(3), 40-41. https://doi.org/10.1007/s41184-017-0060-8

5. De Groot, K., Paans, W., De Veer, A. J. E., \& Francke, A. L. (2017). Knelpunten bij verslaglegging door verpleegkundigen en verzorgenden [Barriers in nursing documentation]. TvZ: Tijdschrift Voor Verpleegkundigen, 127(6), 34-36. https://doi.org/10.1007/s41184-0170129-4 
6. Flemming, D., \& Hübner, U. (2013). How to improve change of shift handovers and collaborative grounding and what role does the electronic patient record system play? Results of a systematic literature review. International Journal of Medical Informatics, 82, 580-592. https://doi.org/10.1016/j.jimedinf.2013.03.004

7. Francke, A. L., Smit, M. C., De Veer, A. J. E., \& Mistiaen, P. (2008). Factors influencing the implementation of clinical guidelines for health care professionals: A systematic meta-review. BMC Medical Informatics and Decision Making, 8(1), 38. https://doi.org/10.1186/1472-6947-838

8. Jefferies, D., Johnson, M., \& Griffiths, R. (2010). A meta-study of the essentials of quality nursing documentation. International Journal of Nursing Practice, 16, 112-124. https://doi.org/10.1111/j.1440-172X.2009.01815.x

9. Kelley, T. F., Brandon, D. H., \& Docherty, S. L. (2011). Electronic nursing documentation as a strategy to improve quality of patient care. Journal of Nursing Scholarship, 43(2), 154-162. https://doi.org/10.1111/j.1547-5069.2011.01397.x

10. Kieft, R. A. M. M., Vree e, E. M., De Groot, E. M., De Graaf-Waar, H., Van Gool, C. H., Koster, N., Delnoij, D. M. J. (2018). Mapping the Dutch SNOMED CT subset to Omaha System, NANDA International and International Classification of Functioning, Disability and Health. International Journal of Medical Informatics, 82(7), 580-592.

https://doi.org/10.1016/j.jimedinf.2017.12.025

11. Kieft, R. A. M. M., Vreeke, E. M., De Groot, E. M., Volkert, P. A., Francke, A. L., \& Delnoij, D. M. J. (2017). The development of a nursing subset of patient problems to support interoperability. BMC Medical Informatics \& Decision Making, 17(1), 158. https://doi.org/10.1186/s12911-0170567-5

12. Lavin, M. A., Harper, E., \& Barr, N. (2015). Health information technology, patient safety and professional nursing care documentation in acute care settings. Online Journal of Issues in Nursing, 20(2), 6. https://doi.org/10.3912/OJIN.Vol20No02PPT04

13. Matic, J., Davidson, P. M., \& Salamonson, Y. (2010). Review: Bringing patient safety to the forefront through structured computerisation during clincal handover. Journal of Clinical Nursing, 20(1), 184-189. https://doi.org/10.1111/j.1365-2702.2010.03242.x

14. Meissner, A., \& Schnepp, W. (2014). Staff experiences within the implementation of computerbased nursing records in residential aged care facilities: A systematic review and synthesis of qualitative research. BMC Medical Informatics \& Decision Making, 14, 54. https://doi.org/10.1186/1472-6947-14-54

15. Mistiaen, P., Francke, A. L., \& Poot, E. (2007). Interventions aimed at reducing problems in adult patients discharged from hospital to home: A systematic meta-review. BMC Health Services Research, 7(7),47. https://doi.org/10.1186/1472-6963-7-47

16. Moher, D., Liberati, A., Tetzlaff, J., Altman, D. G., \& PRISMA Group. (2009). Preferred reporting items for systematic reviews and metaanalyses: The PRISMA statement. PloS Medicine, 6(7), e1000097. https://doi.org/10.1371/journal.pmed.1000097

17. Müller-Staub, M., De Graaf-Waar, H., \& Paans, W. (2016). An internationally consented standard for nursing process-clinical decision support systems in electronic health records. Computers, Informatics, Nursing, 34(11), 493-502. https://doi.org/10.1097/CIN.0000000000000277

18. Müller-Staub, M., Lavin, M. A., Needham, I., \& van Achterberg, T. (2006). Nursing diagnoses, interventions and outcomes - application and impact on nursing practice: Systematic review. Journal of Advanced Nursing, 56(5), 514-531. https://doi.org/10.1111/j.13652648.2006.04012.x

19. Müller-Staub, M., Needham, I., Odenbreit, M., Lavin, M. A., \& van Achterberg, T. (2007). Improved quality of nursing documentation: Results of a nursing diagnoses, interventions and 
outcomes implementation study. International Journal of Nursing Terminologies and Classifications, 18(1), 5-17. https://doi.org/10.1111/j.1744-618X.2007.00043.x

20. Paans, W., Nieweg, R. M., van der Schans, C. P., \& Sermeus, W. (2011). What factors influence the prevalence and accuracy of nursing diagnoses documentation in clinical practice? A systematic literature review. Journal of Clinical Nursing, 20(17-18), 2386-2403. https://doi.org/10.1111/j.1365-2702.2010.03573.x

21. Paans, W., Sermeus, W., Nieweg, R. M., \& Van der Schans, C. P. (2010). Prevalence of accurate nursing documentation in patient records. Journal of Advanced Nursing, 66(11), 24812489. https://doi.org/10.1111/j.1365-2648.2010.05433.x

22. Randorff Højen, A., \& Rosenbeck Gøeg, K. (2012). SNOMED CT Implementation. Methods of Information in Medicine, 51, 529-538. https://doi.org/10.3414/ME11-02-0023

23. Riesenberg, L. A., Leitzsch, J., \& Cunningham, J. M. (2010). Nursing handoffs: A systematic review of the literature. American Journal of Nursing, 110(4), 24-34. https://doi.org/10.1097/01.NAJ.0000370154.79857.09

24. Shea, B. J., Bouter, L. M., Peterson, J., Boers, M., Andersson, N., Ortiz, Z., Grimshaw, J. M. (2007). External validation of a measurement tool to assess systematic reviews (AMSTAR). PLoS ONE, 2(12), e1350. https://doi.org/10.1371/journal.pone.0001350

25. Shea, B. J., Grimshaw, J. M., Wells, G. A., Boers, M., Andersson, N., Hamel, C., Bouter, L. M. (2007). Development of AMSTAR: A measurement tool to assess the methodological quality of systematic reviews. BMC Medical Research Methodology, 7, 10. https://doi.org/10.1186/14712288-7-10

26. Smith, V., Devane, D., Begley, C. M., \& Clarke, M. (2011). Methodology in conducting a systematic review of systematic reviews of healthcare interventions. BMC Medical Research Methodology, 11(1), 15. https://doi.org/10.1186/1471-2288-11-15

27. Sockolow, P. S., Liao, C., Chittams, J. L., \& Bowels, K. H. (2012). Evaluating the impact of electronic health records on nurse clinical process at two community health sites. Nursing Informatics, 2012, 381.

28. Staggers, N., \& Blaz, J. W. (2013). Research on nursing handoffs for medical and surgical setttings: An integrative review. Journal of Advanced Nursing, 69(2), 247-262. https://doi.org/10.1111/j.1365-2648.2012.06087.x

29. Tastan, S., Linch, G. C., Keenan, G. M., Stifter, J., McKinney, D., Fahey, L., Wilkie, D. J. (2014). Evidence for the existing American Nurses Association-recognized standardized nursing terminologies: A systematic review. International Journal of Nursing Studies, 51(8), 1160-1170. https://doi.org/10.1016/j.ijnurstu.2013.12.004

30. The Office of the National Coordinator for Health Information Technology. (2017). Standard nursing terminologies: A landscape analysis. Retrieved from https://www.healthit.gov/sites/default/files/snt_final_05302017.pdf

31. Tuinman, A., De Greef, M. H. G., Krijnen, W. P., Paans, W., \& Roodbol, P. F. (2017). Accuracy of documentation in the nursing care plan in long-term institutional care. Geriatric Nursing, 38(6), 578-583. https://doi.org/10.1016/j.gerinurse.2017.04.007

32. Urquhart, C., Currell, R., Grant, M. J., \& Hardiker, N. R. (2009). Nursing record systems: Effects on nursing practice and healthcare outcomes. Cochrane Database of Systematic Reviews, 21(1), CD002099. https://doi.org/10.1002/14651858.cd002099.pub2

33. Verheij, R. A., Curcin, V., Delaney, B. C., \& McGilchrist, M. (2018). Possible sources of bias in primary care electronic health record data (re-) use. Journal of Medical Internet Research, 20(5), e185. https://doi.org/10.2196/jmir.9134

34. Wang, N., Hailey, D., \& Yu, P. (2011). Quality of nursing documentation and approaches to its evaluation: A mixed-method systematic review. Journal of Advanced Nursing, 67(9), 18581875. https://doi.org/10.1111/j.1365-2648.2011.05634.x 
35. Westra, B., Latimer, G., Matney, S., Park, J., Sensmeier, J., Simpson, R., Delaney, C. (2015). A national action plan for sharable and comparable nursing data to support practice and translation research for transforming health care. Journal of the American Medical Informatics Association, 22(3), 600-607. https://doi.org/10.1093/jamia/ocu011

36. Wouters, M., Swinkels, I., Sinnge, J., De Jong, J., Brabers, A., Van Lettow, B., Van Gennip, L. (2017). Kies bewust voor eHealth: eHealthmonitor 2017 [Choose deliberately for eHealth: eHealthmonitor 2017]. Retrieved from https://www.nictiz.nl/programmas/e-health-monitor/ ehealth-monitor-2017/

\section{Tables and figures}

FIGURE 1 PRISMA flow diagram

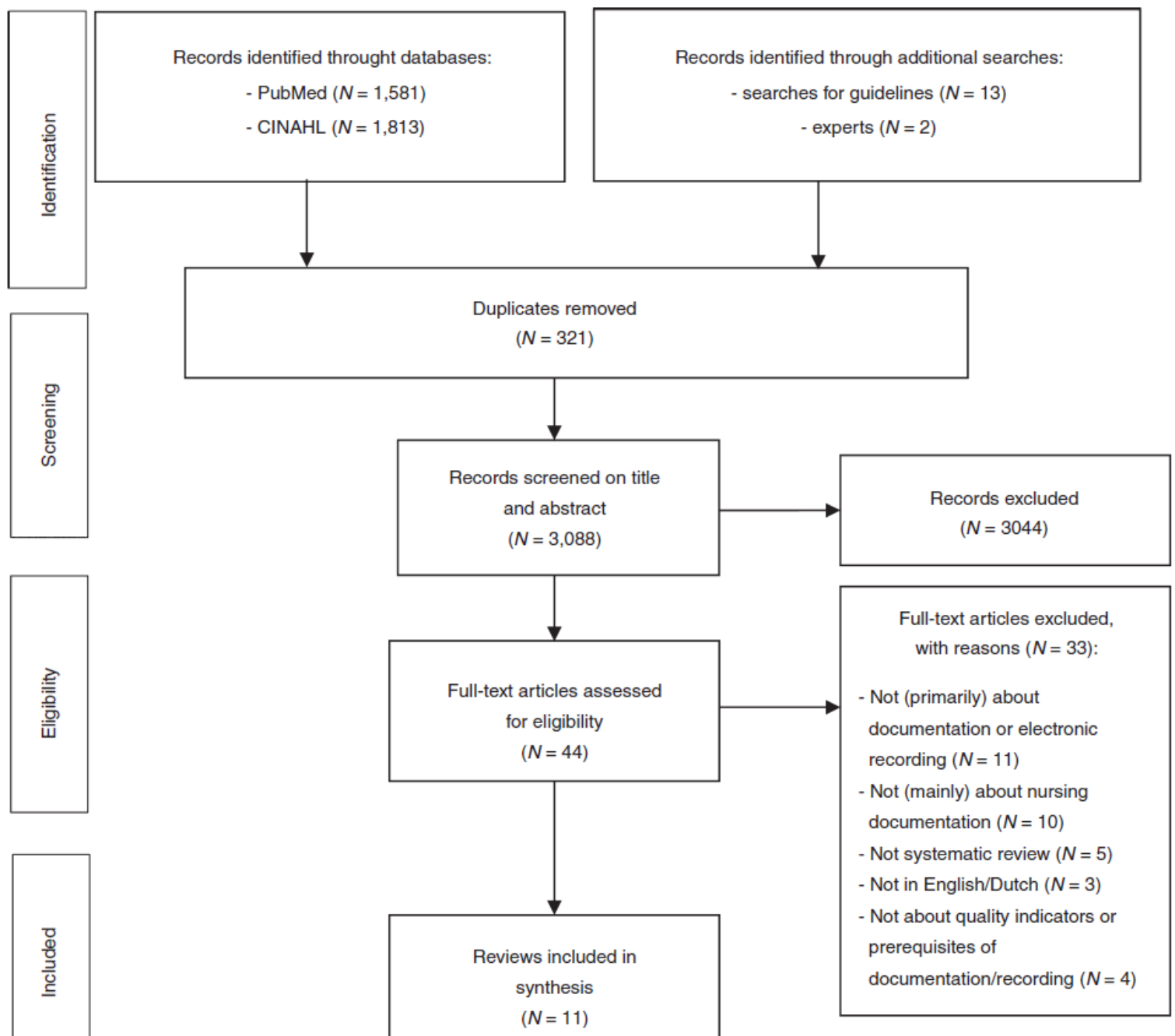


TABLE 1 Methodological quality and funding source of the reviews included

\begin{tabular}{|c|c|c|c|c|c|c|c|c|c|c|c|c|c|c|c|}
\hline \multirow[b]{2}{*}{ Study ID } & \multicolumn{12}{|c|}{ AMSTAR scores" } & \multirow{2}{*}{$\begin{array}{l}\text { Total } \\
\text { AMSTAR } \\
\text { score }\end{array}$} & \multirow[b]{2}{*}{$\begin{array}{l}\text { Methodological } \\
\text { quality }\end{array}$} & \multirow[b]{2}{*}{ Funding source } \\
\hline & $\begin{array}{l}\text { Question } \\
1^{\mathrm{b}}\end{array}$ & $\begin{array}{l}\text { Question } \\
2^{\mathrm{c}}\end{array}$ & $\begin{array}{l}\text { Question } \\
3^{d}\end{array}$ & $\begin{array}{l}\text { Question } \\
4^{*}\end{array}$ & $\begin{array}{l}\text { Question } \\
5^{\prime}\end{array}$ & $\begin{array}{l}\text { Question } \\
6^{8}\end{array}$ & $\begin{array}{l}\text { Question } \\
7^{h}\end{array}$ & $\begin{array}{l}\text { Question } \\
8^{i}\end{array}$ & $\begin{array}{l}\text { Question } \\
\text { gi }\end{array}$ & $\begin{array}{l}\text { Question } \\
10^{k}\end{array}$ & $\begin{array}{l}\text { Question } \\
11^{\prime}\end{array}$ & $\begin{array}{l}\text { Question } \\
12^{\mathrm{m}}\end{array}$ & & & \\
\hline $\begin{array}{l}\text { Blair and } \\
\text { Smith (2012) }\end{array}$ & 1 & 1 & 0 & 0 & 0 & 0 & 0 & 0 & 1 & 0 & 0 & 0 & 3 & Low & Not reported \\
\hline $\begin{array}{l}\text { Jefferies et al. } \\
\text { (2010) }\end{array}$ & 1 & 1 & 1 & 0 & 1 & 1 & 1 & 0 & 0 & 0 & 0 & ca. & 6 & Average & Not reported \\
\hline $\begin{array}{l}\text { Matic et al. } \\
\text { (2010) }\end{array}$ & 1 & 1 & 1 & 0 & 0 & 0 & 0 & 0 & 0 & 0 & 0 & ca. & 3 & Low & Not reported \\
\hline $\begin{array}{l}\text { Meissner and } \\
\text { Schnepp } \\
\text { (2014) }\end{array}$ & 1 & 1 & 0 & 0 & 1 & 1 & 0 & 0 & 1 & 0 & 1 & 0 & 6 & Average & $\begin{array}{l}\text { No funding source from any } \\
\text { agency }\end{array}$ \\
\hline $\begin{array}{l}\text { Paans et al. } \\
\text { (2011) }\end{array}$ & 1 & 1 & 0 & 1 & 0 & 1 & 0 & 0 & 1 & 0 & 1 & ca. & 6 & Average & $\begin{array}{l}\text { Brink\&Research and Development } \\
\text { Association, Utrecht, the } \\
\text { Netherlands }\end{array}$ \\
\hline $\begin{array}{l}\text { Urquhart } \\
\text { et al. (2009) }\end{array}$ & 1 & 1 & 1 & 1 & 1 & 1 & 1 & 1 & 1 & 1 & 1 & ca. & 11 & High & $\begin{array}{l}\text { The Wales Office of Research } \\
\text { and Development in Health } \\
\text { and Social Care; Department } \\
\text { of Health (England) Incentive } \\
\text { Scheme for Cochrane reviews } \\
\text { and updates }\end{array}$ \\
\hline $\begin{array}{l}\text { Wang } \\
\text { et al. (2011) }\end{array}$ & 1 & 1 & 0 & 0 & 0 & 1 & 0 & 0 & 1 & 0 & 0 & ca. & 4 & Low & $\begin{array}{l}\text { Australia Research Council (ARC); } \\
\text { Aged and Community Services } \\
\text { Austrafia; lllawarra Retirement } \\
\text { Trust; RSL Care; Uniting Care } \\
\text { Ageing South Eastern Region; } \\
\text { Warrigal care }\end{array}$ \\
\hline
\end{tabular}

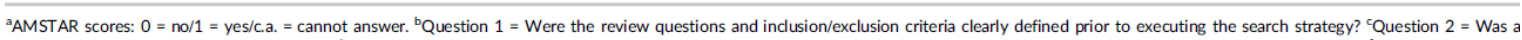

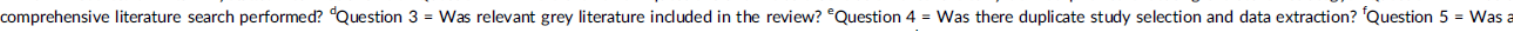
list of studies (included and excluded) provided? ${ }^{8}$ Question 6 = Were the characteristics of the included studies provided? "Question 7 = Was the risk of bias assessed for each included study, taking into account important potential confounders and other sources of bias relevant to the review question? 'Question 8 = Was the quality of the body of evidence appropriately assessed and considered in formulating the conclusions of the review? 'Question $9=$ Were the data appropriately synthesized in a qualitative manner and if applicable, was heterogeneity assessed? 'Question $10=$ Was the likelihood of publication bias assessed? 'Question 11 = Were conflicts of interest disclosed for all of the review authors and was the funding source of the review and of each study within the review reported? "'Question 12 = Were relevant subgroups considered in the review process, analysis, and conclusions?

TABLE 2 Extraction table giving quality criteria for nursing documentation

\begin{tabular}{|c|c|c|c|}
\hline Study ID and methodological quality & General quality criteria for nursing documentation & Quality criteria concerning the nursing process & $\begin{array}{l}\text { Quality criteria concerning } \\
\text { nursing terminologies and } \\
\text { unambiguous language }\end{array}$ \\
\hline Blair and Smith (2012) Low quality & $\begin{array}{l}\text { Concise/brief, clear, accurate, and useful/relevant } \\
\text { information; structured; no repetitive information; } \\
\text { reflecting the nursing process; limited use of } \\
\text { abbreviations; legible and legally prudent; not } \\
\text { disease-focused but patient-centred; and evidence of } \\
\text { clinical decision-making and critical thinking }\end{array}$ & $\begin{array}{l}\text { Nursing documentation must reflect the observations, } \\
\text { actions and outcomes of care } \\
\text { Evidence of clinical decision-making and critical } \\
\text { thinking must be documented } \\
\text { Use of the focus charting method is recommended } \\
\text { Several models reflecting (steps in) nursing process } \\
\text { are mentioned, viz: VIPS model; SOAP/SOAPIE; } \\
\text { HOAP; Focus charting method (DAR and AIE) }\end{array}$ & $\begin{array}{l}\text { NANDA is mentioned as a tool to } \\
\text { enhance the quality of nursing } \\
\text { documentation } \\
\text { The professional challenge of } \\
\text { standardizing the language used } \\
\text { is mentioned }\end{array}$ \\
\hline Flemming and Hübner (2013) Average quality & $\begin{array}{l}\text { Accurate and up to date; complete, relevant, clinically } \\
\text { necessary, congruent, personalized, both quantitative } \\
\text { (numbers/facts) and subjective, both retrospective } \\
\text { and prospective, with common set of information for } \\
\text { various professions } \\
\text { Containing both factual patient information and } \\
\text { detailed personal information on specific items (i.e., } \\
\text { reason for admission, clinical condition/active } \\
\text { medical problem, medication, and other treatments, } \\
\text { to-dos and care plan, rationale of task/plan), } \\
\text { information on disagreement and anticipatory } \\
\text { guidance or recommendations, traceability of } \\
\text { decisions }\end{array}$ & $\begin{array}{l}\text { To-dos and care plan, rationale of plan, traceability of } \\
\text { decisions must be documented }\end{array}$ & $\begin{array}{l}\text { Use of the SBAR method is } \\
\text { recommended to structure and } \\
\text { systematize information }\end{array}$ \\
\hline Jefferies et al. (2010) Average quality & $\begin{array}{l}\text { 1. Nursing documentation should be patient centred; } \\
\text { 2. Nursing documentation must contain the actual } \\
\text { work of nurses including education and } \\
\text { psychosocial support; } \\
\text { 3. Nursing documentation is written to reflect the } \\
\text { objective clinical judgement of the nurse; } \\
\text { 4. Nursing documentation must be presented in a } \\
\text { logical and sequential manner, } \\
\text { 5. Nursing documentation should be written } \\
\text { contemporaneously, or as events occur; } \\
\text { 6. Nursing documentation should record variances in } \\
\text { care within and beyond the healthcare record; } \\
\text { 7. Nursing documentation should fulfil legal } \\
\text { requirements }\end{array}$ & Not defined & Not defined \\
\hline Kelley et al. (2011) Low quality & $\begin{array}{l}\text { Documentation should be based on the patient } \\
\text { information needed to give safe high-quality care }\end{array}$ & Not defined & Not defined \\
\hline Matic et al. (2010) Low quality & $\begin{array}{l}\text { Information must be patient-centred and less } \\
\text { subjectively documented to inform clinical decision- } \\
\text { making }\end{array}$ & Not defined & Not defined \\
\hline
\end{tabular}




\begin{tabular}{|c|c|c|c|}
\hline Study ID and methodological quality & General quality criteria for nursing documentation & Quality criteria concerning the nursing process & $\begin{array}{l}\text { Quality criteria concerning } \\
\text { nursing terminologies and } \\
\text { unambiguous language }\end{array}$ \\
\hline Meissner and Schnepp (2014) Average quality & $\begin{array}{l}\text { Continuous and complete information. Factually and } \\
\text { professionally correct } \\
\text { Providing a broad and holistic view of resident. } \\
\text { Consistent and legible }\end{array}$ & Not defined & Not defined \\
\hline Paans et al. (2011) Average quality & $\begin{array}{l}\text { Clear diagnostic language, clinical reasoning, PES } \\
\text { structure }\end{array}$ & $\begin{array}{l}\text { A central element of the nursing process is how } \\
\text { nurses derive a nursing diagnosis based on clinical } \\
\text { assessments, interviews, and observations } \\
\text { Evidence of clinical reasoning must be documented }\end{array}$ & $\begin{array}{l}\text { Clear diagnostic language is } \\
\text { recommended, for example, by } \\
\text { using the NANDA classification } \\
\text { Use of formats such as the PES } \\
\text { structure is recommended } \\
\text { Use of standardized nursing care } \\
\text { plans is mentioned }\end{array}$ \\
\hline Riesenberg et al. (2010) Average quality & Accurate, congruent, and complete & Not defined & $\begin{array}{l}\text { SBAR is mentioned as the most } \\
\text { frequently cited mnemonic }\end{array}$ \\
\hline Staggers and Blaz (2013) Average quality & $\begin{array}{l}\text { Information completeness, accuracy, effectiveness, } \\
\text { and efficiency }\end{array}$ & Not defined & Use of SBAR is mentioned \\
\hline Urquhart et al. (2009) High quality & $\begin{array}{l}\text { Quality aspects of nursing documentation: overall } \\
\text { quality, legibility, and quantity of documentation; } \\
\text { number of nursing diagnoses, (vital) signs, } \\
\text { interventions, and activities documented; time } \\
\text { needed for documentation, time spent on logging } \\
\text { and validation activities, time needed for shift } \\
\text { change, time needed for the reviewing and writing } \\
\text { of medical and nurses' notes }\end{array}$ & Not defined & ICIS is mentioned \\
\hline Wang et al. (2011) Low quality & $\begin{array}{l}\text { Three dimensions of nursing documentation: } \\
\text { Format and structure quantity of records; } \\
\text { completeness; legibility, readability; redundancy; use } \\
\text { of abbreviations } \\
\text { Process: signature; designation; date; timeliness; } \\
\text { regularity of documentation; accuracy of } \\
\text { documentation content in relation to reality } \\
\text { Content: } \\
\text { - comprehensiveness of data such as nursing history, } \\
\text { status, baseline data, discharge summary, care needs } \\
\text { and steps in nursing process } \\
\text { - appropriateness in relation to particular care issue, } \\
\text { connected to clinical policies or guidelines, } \\
\text { standardized terminologies, diagnostic statement } \\
\text { (PES format) and steps in nursing process }\end{array}$ & $\begin{array}{l}\text { Content of nursing documentation should correspond } \\
\text { with the five steps of the nursing process: } \\
\text { Assessment, Diagnosis, Goal, Intervention, Evaluation }\end{array}$ & $\begin{array}{l}\text { Use of standardized nursing } \\
\text { terminology is recommended, for } \\
\text { example, ICNP, NANDA, NIC, } \\
\text { NOC } \\
\text { Etc. (see Table } 3 \text { in Wang et al., } \\
\text { 2011) } \\
\text { Standardized nursing language is } \\
\text { mentioned as an essential } \\
\text { requirement for aggregating data } \\
\text { from electronic documentation } \\
\text { systems }\end{array}$ \\
\hline
\end{tabular}

Notes. PES: problem-aetiology-symptoms; SOAP/SOAPIE: subjective data, objective data, assessment, plan, intervention, evaluation and revision; HOAP: history, observation, assessment and plan; SBAR: Situation, Background, Assessment and Recommendation; ICNP: intemational classification of nursing practice; NANDA: North American Nursing Diagnosis Association; NIC: Nursing Intervention Classification; NOC: Nursing Outcome Classification.

TABLE 3 Extraction table giving instruments for measuring the quality of nursing documentation

\begin{tabular}{ll}
\hline Study ID and methodological quality & Instruments used for measurement of the quality of nursing documentation \\
\hline Blair and Smith (2012) Low quality & Not defined \\
\hline Flemming and Hübner (2013) Average quality & Structured checklists, mnemonics, or minimum data sets derived from SBAR are recommended \\
\hline Jefferies et al. (2010) Average quality & Not defined \\
\hline Kelley et al. (2011) Low quality & Not defined \\
\hline Matic et al. (2010) Low quality & Development of minimum datasets is recommended \\
\hline Meissner and Schnepp (2014) Average quality & Not defined \\
\hline Paans et al. (2011) Average quality & $\begin{array}{l}\text { Several available instruments are described: } \\
\text { D-Catch instrument; the QOD; the Scale for Degrees of Accuracy; and the Q-DIO }\end{array}$ \\
\hline Riesenberg et al. (2010) Average quality & $\begin{array}{l}\text { Mnemonics are identified, based on SBAR } \\
\text { Staggers and Blaz (2013) Average quality }\end{array}$ \\
\hline Urquhart et al. (2009) High quality & $\begin{array}{l}\text { Not defined } \\
\text { Wang et al. (2011) Low quality }\end{array}$ \\
& $\begin{array}{l}\text { Four most commonly used instruments: Ehnfors and Smedby's comprehensiveness-in-recording } \\
\text { instrument; the Cat-ch-Ing instrument; Q-DIO instrument; and an audit protocol for } \\
\text { documentation of the assessment, treatment, and prevention of pressure ulcers }\end{array}$ \\
\hline
\end{tabular}

Notes. SBAR: Situation, Background, Assessment and Recommendation; QOD: quality of nursing diagnoses; Q-DIO; quality of nursing diagnoses interventions and outcomes. 
TA BLE 4 Extraction table giving requirements for electronic nursing documentation

\begin{tabular}{|c|c|c|}
\hline $\begin{array}{l}\text { Study ID and } \\
\text { methodological quality }\end{array}$ & Requirements for electronic nursing documentation & Preconditions for electronic nursing documentation \\
\hline $\begin{array}{l}\text { Blair and Smith (2012) } \\
\text { Low quality }\end{array}$ & $\begin{array}{l}\text { User-friendly clinical systems and tools } \\
\text { Easy access; easy to use, locate, and retrieve information; quick } \\
\text { and efficient, not time consuming/ittle workoad; supporting } \\
\text { problem-solving lencouraging the identification of patient } \\
\text { problems and to link those problems to functional health } \\
\text { patterns); can be used by many health disciplines/professionals } \\
\text { [Note: not specifically concerning electronic documentation] }\end{array}$ & $\begin{array}{l}\text { Continuing education should be timely, readily available, } \\
\text { and particularly focused on diagnostic reasoning and } \\
\text { critical thinking } \\
\text { Information technology, electronic record keeping. } \\
\text { computer equipment, portable computers } \\
\text { Standardizing the language used } \\
\text { Managing the change from paper to electronic records } \\
\text { Computer experience (staff) } \\
\text { Support from staff } \\
\text { Documenting throughout the shift (rather than waiting } \\
\text { until the end) } \\
\text { Combine with effective (verbal) communication }\end{array}$ \\
\hline $\begin{array}{l}\text { Flemming and Hübner } \\
\text { (2013) Average quality }\end{array}$ & $\begin{array}{l}\text { Electronic patient record systems play an important role in } \\
\text { documenting up to date patient information in a structured } \\
\text { way (mostly retrospective facts), but lack important pieces of } \\
\text { information (prospective and subjective) to support } \\
\text { communicating "the full story" of the patient } \\
\text { Both qualitative (holistic, subjective) information and numbers } \\
\text { (facts) are needed for "the full story" of a patient } \\
\text { There is some evidence for the superiority of electronic } \\
\text { handover systems compared to paper-based approaches: } 10 \\
\text { out of } 16 \text { "pure evaluation studies" (pre-post-design) supported } \\
\text { this superiority. With an overall ranking: } 1 \text {. computerized and } \\
\text { discussed, } 2 \text {. in-person handovers, } 3 \text {. technology only }\end{array}$ & $\begin{array}{l}\text { Structured forms and data sheet based handovers must } \\
\text { not detract clinicians' attention from critical care } \\
\text { issues; the structured nature must not be a problem } \\
\text { for summarizing the clinical case }\end{array}$ \\
\hline $\begin{array}{l}\text { Jefferies et al. (2010) } \\
\text { Average quality }\end{array}$ & Not defined & Not defined \\
\hline $\begin{array}{l}\text { Kelley et al. (2011) Low } \\
\text { quality }\end{array}$ & Not defined & $\begin{array}{l}\text { Predetermined drop-down menus can be beneficial to } \\
\text { some nurses, but potential risks of the structured } \\
\text { format andior dectronic documentation are: } \\
\text { - make it easy for nurses to not think about the nursing } \\
\text { care process; } \\
\text { - the copy-and-paste feature increases the risk of } \\
\text { pasting data that may no longer be applicable or } \\
\text { accurate; } \\
\text { - to limit the full description of the patient's health } \\
\text { status. Having documentation standards based on the } \\
\text { patient information needed to give safe high-quality } \\
\text { care could help in designing and optimizing the use of } \\
\text { electronic nursing documentation systems }\end{array}$ \\
\hline $\begin{array}{l}\text { Matic et al. } \\
\text { (2010) Low quality }\end{array}$ & $\begin{array}{l}\text { Efficacy of electronic tools is dependent on the quality of the } \\
\text { programme and its design } \\
\text { This review showed some potential advantages of electronic } \\
\text { tools }\end{array}$ & $\begin{array}{l}\text { The less subjective the clinical handover is and the more } \\
\text { reliable and valid the information given, the greater the } \\
\text { likelihood of a robust handover } \\
\text { There needs to be greater attention to what the integral } \\
\text { elements of a nursing handover are from a } \\
\text { comprehensive and patient-centred approach. The } \\
\text { design of these tools should be informed by } \\
\text { communication theory, considering cultural and } \\
\text { linguistic factors }\end{array}$ \\
\hline $\begin{array}{l}\text { Meissner and Schnepp } \\
\text { (2014) Average quality }\end{array}$ & $\begin{array}{l}\text { Easy access to charts and medical information; offering a fast } \\
\text { overview; easy to read; readily available, easy to check and } \\
\text { monitor information on care, activities, regulatory compliance } \\
\text { issues, staff education needs; performance appraisal; easy to } \\
\text { enter data; providing automatic alerts to help check plausibility; } \\
\text { enabling a quick response to residents' care needs; enabling } \\
\text { quicker and easier care decisions; simplifying/facilitating dally } \\
\text { work; saving time }\end{array}$ & $\begin{array}{l}\text { Helping staff to think about what to assess and to } \\
\text { identify problems } \\
\text { Teaching/gyidance of staff } \\
\text { Equipment availability, software, technical functionality } \\
\text { This review shows some evidence on promoting and } \\
\text { hindering factors for the implementation of electronic } \\
\text { nursing documentation systems }\end{array}$ \\
\hline
\end{tabular}

(Continues) 
TABLE 4 (Continued)

\begin{tabular}{|c|c|c|}
\hline $\begin{array}{l}\text { Study ID and } \\
\text { methodological quality }\end{array}$ & Requirements for electronic nursing documentation & Preconditions for electronic nurs ing documentation \\
\hline $\begin{array}{l}\text { Paans et al. (2011) } \\
\text { Average quality }\end{array}$ & Not defined & $\begin{array}{l}\text { Influencing factors (in } 4 \text { domains and } 18 \text { subthemes): (1) } \\
\text { nurse as diagnostician: } 1.1 \text { attitude, } 1.2 \text { diagnostic } \\
\text { experience and expertise, } 1.3 \text { knowledge, } 1.4 \\
\text { diagnostic reasoning skills; (2) educational or resources } \\
\text { related: } 2.1 \text { guided clinical reasoning, } 2.2 \text { educational } \\
\text { backgound in nursing process application, } 2.3 \\
\text { prestructured record forms, } 2.4 \text { classification systems, } \\
2.5 \text { computer-generated care plans and patient records; } \\
\text { (3) complexity of a patient's situation: } 3.1 \text { cultural } \\
\text { differences, } 3.2 \text { patients' severe medical diagnosis in } \\
\text { special ty areas } 3.3 \text { patients' way of expressing diagnoses; } \\
\text { (4) hospital policy and environment } 4.1 \text { number of patients } \\
\text { per nurse, } 4.2 \text { nurses' workoad level and time to spend on } \\
\text { diagnostic tasks, } 4.3 \text { use of a medical model, } 4.4 \text { number } \\
\text { of administrative tasks } 4.5 \text { physicians' disposition towards } \\
\text { nursing diagnoses } 4.6 \text { information structure used. } \\
\text { Other factors: } \\
\text { Nursing diagnostic language, support from hospital } \\
\text { management, policy on diagnostic tasks, guided clinical } \\
\text { reasoning, prestructured record forms, computer- } \\
\text { gener ated standardized care plans and patient records }\end{array}$ \\
\hline $\begin{array}{l}\text { Riesenberg et al. (2010) } \\
\text { Average quality }\end{array}$ & Not defined & $\begin{array}{l}\text { Use of standard formats is recommended. These formats } \\
\text { have to be adapted for each nursing area } \\
\text { Strategies for effective handoffs: communication skills, } \\
\text { standardzation strategies technological solutions, } \\
\text { environmental strategies, training and education, staff } \\
\text { involvement, leadership }\end{array}$ \\
\hline $\begin{array}{l}\text { Staggers and Blaz } \\
\text { (2013) Average quality }\end{array}$ & Not defined & $\begin{array}{l}\text { Use of structured, consistent formats is recommended. } \\
\text { These formats should be tailored to individual units } \\
\text { Handoffs should be supported and not replaced by } \\
\text { technology, a combination of written and verbal } \\
\text { reports (minimizing information decrements); using } \\
\text { standardized/structured formats or templates } \\
\text { (improving information completeness, efficiency- } \\
\text { decreased average time and costs - and information } \\
\text { recall rates); agreement on a specific format; } \\
\text { consistency and predictab ility of information transfer; } \\
\text { nurses being amenable to technology-supported } \\
\text { handoffs; considering context, with specific content } \\
\text { and methods depending on contexts (e.g., patient } \\
\text { condition, nurse expertise, handoff method; unit norms, } \\
\text { expectations, and codes of behaviour;, precise content } \\
\text { (to support nurses' decision-making. planning for care, } \\
\text { and for detecting critical information) }\end{array}$ \\
\hline $\begin{array}{l}\text { Urquhart et al. (2009) } \\
\text { High quality }\end{array}$ & $\begin{array}{l}\text { Not defined } \\
\text { No evidence of any measurable difference in the effects of a } \\
\text { computerized nursing record system (vs. manual or paper- } \\
\text { based; neither effects on nursing practice nor patient } \\
\text { outcomes) }\end{array}$ & Not defined \\
\hline $\begin{array}{l}\text { Wang et al. (2011) Low } \\
\text { quality }\end{array}$ & Not defined & $\begin{array}{l}\text { EHRs, education and organizational support for } \\
\text { documentation of the nursing process, the use of } \\
\text { standardized nursing languages/classifications (NANDA, } \\
\text { NIC, and NOC), and nursing theories (e.g., Eriksson's } \\
\text { caring theory) could improve documentation } \\
\text { A proper process of data capture is expected as it } \\
\text { enables documentation of valid and reliable information } \\
\text { about patients and care }\end{array}$ \\
\hline
\end{tabular}

EHRs: electronic health records; NANDA: North American Nursing Diagnosis Association; NIC: Nursing Intervention Classification; NOC: Nursing Out come Classification. 